\title{
Comparative study of coagulation profile in liver disease in tertiary care hospital
}

\author{
Prashant Patel ${ }^{1}$, Urvashi Mangar, ${ }^{2, *}$, R.D Patel ${ }^{3}$ \\ ${ }^{1}$ Consultant Pathologist, Kiran Multisuperspeciality Hospital and Research Center, Surat, Gujarat, ${ }^{2}$ Assistant Professor, Dept. of \\ Pathology, GMERS Medical College, Vadnagar, Gujarat, ${ }^{3}$ Professor, Dept. of Pathology, Banas Medical College, Palanpur,
} Gujarat, India

\section{*Corresponding Author: Urvashi Mangar}

Email: drurvc80@gmail.com

Received: $21^{\text {st }}$ April, 2018

Accepted: $26^{\text {th }}$ June, 2018

\begin{abstract}
Introduction: The liver is the corner stone of the coagulation system and patients with liver disease are at a substantially increase risk of both thrombosis and haemorrhage. Liver acts as a reticulo endothelial system and regulates coagulation and fibrinolysis by removing these coagulation factors from the circulation. Coagulation disorders in liver disease are usually measured by the prolongation of global screening tests such as the prothrombin time and the activated partial thromboplastin time. Ingeneral, PT determines vitamin $\mathrm{K}$ dependent extrinsic factors VII, X, II, V and fibrinogen. The aPTT measures the activities of intrinsic and common pathways of coagulation cascade most sensitive to factor VIII, IX, XI, XII and those of the contact system.

Aims and Objectives: To study the alteration in coagulation profile in various liver diseases, to evaluate the risk of bleeding in patients with liver disease and to study the association of coagulation abnormality with the extent of liver disease.

Material and Methods: The study included 100 patients with liver diseases attending Medicine and Paediatric department clinics in a teaching tertiary care hospital. These patients were divided into three groups: (1) 40 cases of cirrhosis, (2) 40 cases of viral hepatitis and (3) 20 cases of obstructive jaundice. All these patients were screened for different coagulation tests like Prothrombin time (PT), Activated Partial Thromboplastin Time (APTT), Fibrinogen and Platelet count.

Conclusion: Various abnormalities of coagulation tests vary greatly with different liver disorders, duration of the disorders, and their severity. There are more chances of bleeding when coagulation parameters are altered in cases of cirrhosis but more studies are required in this field to evaluate the thrombotic events seen in patients with liver diseases.
\end{abstract}

Keywords: Bleeding time, Coagulation, Cirrhosis, Hepatitis, Obstructive jaundice.

\section{Introduction}

The study of coagulation can be traced back to about $400 \mathrm{BC}$ and to the father of Medicine, Hippocrates. The liver is the corner stone of the coagulation system and patients with liver disease are at a substantially increase risk of both thrombosis and haemorrhage. ${ }^{1}$ Additionally, it acts as a reticulo endothelial system and regulates coagulation and fibrinolysis by removing these coagulation factors from the circulation. As the liver is a highly vascularized organ, liver diseases can alter the abdominal blood flow and predispose patients to significant bleeding problems. Impaired haemostasis resulting from abnormal liver function has multifactorial etiology like impaired coagulation factor synthesis, synthesis of coagulation factors with altered function, increased consumption of coagulation factors and altered clearance of coagulation factors. Coagulation disorders in liver disease are usually measured by the prolongation of global screening tests such as the prothrombin time (PT) and the activated partial thromboplastin time (aPTT). ${ }^{2}$ PT determines the time needed for the platelet poor plasma to clot after the addition of tissue factor (thromboplastin) and calcium chloride. Whereas aPTT determines the time needed for the platelet poor plasma to clot when mixed with a particulate or soluble activator of the contact coagulation factors (factor XII, pre-kallikrein and high- molecular-weight kininogen) and negatively charged phospholipids such as platelet substitutes. ${ }^{3}$ PT determines vitamin $\mathrm{K}$ dependent extrinsic factors VII, $\mathrm{X}, \mathrm{II}, \mathrm{V}$ and fibrinogen. The aPTT measures the activities of intrinsic and common pathways of coagulation cascade most sensitive to factor VIII, IX, XI, XII and those of the contact system. ${ }^{4}$

\section{Aims and Objectives}

1. To study the alteration in coagulation profile in various liver diseases.

2. To evaluate the risk of bleeding in patients with liver disease,

3. To study the association of coagulation abnormality with the extent of liver disease.

\section{Materials and Methods}

This is a prospective study which was carried out in the Department of Pathology, Government Medical college, Surat during the period of June 2014 to January 2017. Total 100 cases of liver diseases were studied. All these cases were selected from medicine and paediatric department. Patients who present with positive liver disease were included in this study. All those patients who were not ready to give complete history and with known case of malignancy were excluded from our study. Out of these 100 cases, 40 
cases were of liver cirrhosis, 40 cases were of viral hepatitis and 20 cases were of obstructive jaundice.

Blood samples from all these patients were drawn under the aseptic precaution and collected in EDTA and citrate vacuitainers. All these semples were sent to central clinical laboratory of the hospital for estimation of five different parametres like Bleeding Time by Ivy's method, Prothrombin Time by Semi Automated Coagulometre (KC1 AMELUNG BIOTRINITY), Activated Partial Thromboplastin Time with Ellegic acid (APTT) by Semi Automated Coagulometre (KC1 AMELUNG BIOTRINITY), Platelet count by Fully
Automated Blood Cell Counter, Sysmex KX-21 and Plasma fibrinogen level estimation by reagent kit Clottable protein.

\section{Results}

This prospective study was carried out in the Department of Pathology, Government Medical college, Surat during the period of June 2014 to January 2017. Total 100 cases of liver diseases were selected and screened for various coagulation studies. Out of 100 cases 70 were male and 30 were females.

Table 1: Coagulation profile in various liver disease

\begin{tabular}{|l|c|c|c|c|c|c|c|c|}
\hline \multirow{2}{*}{ Test } & \multicolumn{2}{c}{$\begin{array}{c}\text { Cirrhosis } \\
\mathbf{n}=\mathbf{4 0}\end{array}$} & \multicolumn{2}{c|}{$\begin{array}{c}\text { Viral hepatitis } \\
\mathbf{n}=\mathbf{4 0}\end{array}$} & $\begin{array}{c}\text { Obstructive jaundice } \\
\text { N=20 }\end{array}$ & \multicolumn{2}{c|}{$\begin{array}{c}\text { Total } \\
\text { n=100 }\end{array}$} \\
\hline & Normal & abnormal & Normal & abnormal & Normal & abnormal & Normal & Abnormal \\
\hline BT & 20 & 20 & 40 & 0 & 20 & 0 & 80 & 20 \\
& $(50 \%)$ & $(50 \%)$ & $(100 \%)$ & & $(100 \%)$ & & $(80 \%)$ & $(20 \%)$ \\
\hline PT & 10 & 30 & 5 & 35 & 0 & 20 & 15 & 85 \\
& $(25 \%)$ & $(75 \%)$ & $(12.5 \%)$ & $(87.5 \%)$ & & $(100 \%)$ & $(15 \%)$ & $(85 \%)$ \\
\hline APTT & 16 & 24 & 24 & 16 & 8 & 12 & 48 & 52 \\
& $(40 \%)$ & $(60 \%)$ & $(60 \%)$ & $(40 \%)$ & $(40 \%)$ & $(60 \%)$ & $(48 \%)$ & $(52 \%)$ \\
\hline PC & 8 & 32 & 40 & 0 & 20 & 0 & 68 & 32 \\
& $(20 \%)$ & $(80 \%)$ & $(100 \%)$ & & $(100 \%)$ & & $(68 \%)$ & $(32 \%)$ \\
\hline FIBRINOGEN & 25 & 15 & 36 & 4 & 17 & 3 & 78 & 22 \\
& $(62.5 \%)$ & $(37.5 \%$ & $(90 \%)$ & $(10 \%)$ & $(85 \%)$ & $(15 \%)$ & $(78 \%)$ & $(22 \%)$ \\
\hline
\end{tabular}

In cirrhosis out of 40 cases, 20 cases (50\%) were bleeders and 20 cases $(50 \%)$ were non bleeder. In bleeder the bleeding time range was 200-400 seconds, mean is $300 \mathrm{sec}$. with S.D. of $100 \mathrm{sec}$, all 20 cases $(100 \%)$ shows rise in PT, in range of 17-35 seconds. Out of 20 cases 18 cases $(90 \%)$ show high value of APTT in range of 40-55 sec.

In Non bleeder the BT range were 180-240 sec. mean value was $210 \mathrm{sec}$. with S.D. of $30 \mathrm{sec} .10$ cases $(50 \%)$ show normal range of PT which is 12-16 seconds and 10 cases $(50 \%)$ show high value in range of 17-35 sec., 14 cases (70\%) were within normal range of APTT 30-40 sec. and 6 cases (30\%) show higher value in range of $40-55 \mathrm{sec}$.,

In bleeder out of 20 cases 8 cases (40\%) show thrombocytopenia with range below 1.5 lac/cumm and 12 cases (60\%) show mild reduction in value with lower limit of normal value in ranges of 1.5 to 2.5 lac/cumm, in bleeder out of 20 cases, 12 cases $(60 \%)$ show hypofibrinogenemia with range of $150-200 \mathrm{mg} \%$ and 8 cases $(40 \%)$ show normal range of fibrinogen $200-250 \mathrm{mg} \%$, in non-bleeders out of 20 cases 3 cases (15\%) show hypofibrinogenemia with range of 150-200 $\mathrm{mg} \%$ and 17 cases $(85 \%)$ show control range of 200 $250 \mathrm{mg} \%$.

In viral hepatitis out of 40 cases, all cases show normal Bleeding Time range of 120-420 sec. with mean value 131.2 sec. and S.D. 16.84 secs. 5 cases $(12.5 \%)$ show PT in normal range of 12-16 sec. 35 cases (87.5\%) show higher value in range of 17-35 sec, 24 cases (60\%) show APTT within normal range of 30-45 sec. and 16 cases $(40 \%)$ show higher value in range of $40-55$ sec. 32 cases $(80 \%)$ show mild decrease in and lower limit of normal value of platelet count in range of 1.5 to 2.5 lac/cumm while 8 cases $(20 \%)$ show normal range of PC 2.5 to 4.5 lac/cumm, 4 cases (10\%) show low fibrinogen level in range of $150-200 \mathrm{mg} \%$ and 27 cases $(67.5 \%)$ show control range of $200-250 \mathrm{mg} \%, 9$ cases $(22.5 \%)$ show upper limit of control value in range of $250-450 \mathrm{mg} \%$.

In obstructive jaundice all 20 cases show bleeding time in normal range of 120-180 sec. with mean of $133.3 \mathrm{sec}$. and S.D. was $15.39 \mathrm{sec}$. All 20 cases $(100 \%)$ show PT higher value in range of 17-35 secs., 8 cases (40\%) show APTT in normal range of 30-40 sec. and 12 cases $(60 \%)$ show high value in range of $40-55,15$ cases $(75 \%)$ show decrease and lower limit of normal value of platelet count and 5 cases $(25 \%)$ show normal value of 2.5 to 4.5 lac/cumm. 3 cases $(15 \%)$ show low fibrinogen level in range of $150-200 \mathrm{mg} \%, 15$ cases (75\%) show control range of $200-250 \mathrm{mg} \%, 2$ cases $(10 \%)$ show lower limit of control value.

\section{Discussion}

This is a prospective study which was carried out in the Department of Pathology, Government Medical college, Surat during the period of June 2014 to January 2017. Total 100 cases of liver diseases were studied. All these cases were selected from medicine and 
paediatric department. Patients who present with positive liver disease were included in this study.

The Bleeding Time reflects reduced platelet count. ${ }^{5}$ Thrombocytopenia is common in patients with liver diseases causing abnormal BT. In cirrhosis the BT in both bleeder \& Non Bleeder is within Normal range, as shown by present study \& other workers study. But the mean value for bleeder is quite higher than non bleeder as shown by Poonam et al in 18 cases with mean range $285 \pm 55.9 \mathrm{sec}$. and present study in 20 cases with mean range $300 \pm 100 \mathrm{sec}$. In present study 40 cases of viral Hepatitis and 20 cases of obstructive Jaundice, the mean range of $\mathrm{BT}$ is of $131.2 \pm 16$ and $133 \pm 15 \mathrm{sec}$. respectively seen which is within normal range of Bleeding time. Similar observation was made by Ratnoff et al, ${ }^{6}$ Donaldson et al ${ }^{7}$ and Singh et al.$^{8}$

The PT is the test widely accepted as a means to monitor patients having disorders of specific coagulation factors in the extrinsic and common pathway of coagulation. Kollar (1973) reported that in mild hepatitis, almost normal prothrombin time were present but the prothrombin time became increasingly prolonged with increasing severity. ${ }^{9}$ Similar observation was also made by Donaldson et al in 1969 . $^{7}$ In cirrhosis, Bleeders shows $100 \%$ elevation of PT by spector and corn et al. ${ }^{10}$ Rastogi $\mathrm{P}$ et al ${ }^{11}$ show $87.5 \%$ elevation, D.S. Singh et $\mathrm{al}^{8}$ shows $100 \%$ elevation and in-present study $100 \%$ elevation of PT is seen in bleeder. In Non-bleeders, Spector and corn et $\mathrm{al}^{10}$ show elevation of PT in 22 cases (55\%) out of 40 studied cases. Rastogi $\mathrm{P}$ shows $18 \%$ elevation and in present study $50 \%$ cases show elevation of PT. ${ }^{11}$ This variation of results may be due to Variation in patients population, Can be attributed to our exclusion of minor degree of bleeding, In patients with liver disease the frequent presence of gastritis and ulcer as well as the oesophageal varices may provide the lesion which permits a haemorrhage which can arise from an organic lesion despite the presence of a normal haemostatic system. In our study, no such patients were found. In viral hepatitis present study shows elevation of PT in 35 cases $(87.5 \%)$ koller (1973) shows similar evaluation in patients with severe hepatitis. ${ }^{9}$

The APTT is the test for intrinsic coagulation pathway. It is especially sensitive for factors XII, IX, XI, XIII, and platelet factor 3 adequacies. In cirrhosis, in bleeders Spector and corn et $\mathrm{al}^{10}$ shows elevation in APTT with Kaolin in 9 cases (64.3\%) cases. Rastogi P et $\mathrm{al}^{11}$ shows elevation in 14 cases $(77.7 \%)$ cases, D.S. Singh et $\mathrm{al}^{8}$ shows elevation in $32(80 \%)$ cases and present study shows elevation of APTT with Kaolin in 18 cases $(90 \%)$ cases. This shows that results are quiet similar in all workers in the range of $65-90 \%$ mild variation may be due to different number of cases study and different population of patients. Similar observation is also made by Donaldson et $\mathrm{al}^{7}$ in 1969. In Non bleeders similar results are obtained by both spector and corn et $\mathrm{al}^{10}$ and present study. Rastogi $\mathrm{P}$ et al did not find any case of elevated APTT with Kaolin. ${ }^{11}$ In viral hepatitis $40 \%$ cases show elevation in APTT with Ellegic acid by present study, similar observation were made by Clark R et al (1973 B). ${ }^{12}$

In cirrhosis Bleeders according to Spector and Corn et $\mathrm{a}^{10}$ thrombocytopenia was seen in $60 \%$ cases with range of $1.98 \pm 0.24$ lac/cumm, Roa PC et al. ${ }^{13}$ shows $70 \%$ cases with range of $1.72 \pm 0.3$, singh et $\mathrm{al}^{8}$ show $100 \%$ cases with range $1.5 \pm 0.5$, Stein SF et al ${ }^{14}$ show in range of $1.99 \pm 0.46 \mathrm{lac} / \mathrm{cumm}$. Rastogi $\mathrm{P}$ et $\mathrm{al}^{11}$ show $100 \%$ cases with range of $1.83 \pm 0.62$ lac/cumm. In present study $100 \%$ cases show thrombocytopenia within range of $1.6 \pm 0.4$ lac/cumm. This shows thrombocytopenia is shown by all workers mostly in similar ways. Low results are seen by Spector and Corn et $\mathrm{a}^{10}$ and Roa PC et al. ${ }^{13}$ It may be due to variation in population of patients and number of cases studied. Harker LA and Finch CA stated that thrombocytopenia is seen mainly due to increased pool of platelets in spleen in cirrhosis with portal hypertension. ${ }^{15}$ In Non-bleeders all workers shown mild thrombocytopenia, but it is less severe than bleeders. Spector and Corn et al[10] show range of $2.06 \pm 0.37$ lac/cumm, Rastogi $\mathrm{P}$ et al ${ }^{11}$ shows range of $2.63 \pm 0.23$ lac/cumm, and in present study range of $2.0 \pm 0.5$ lacs/cumm is seen, which is quite comparable.

In Viral Hepatitis: Roa PC et al ${ }^{13}$ show mild thrombocytopenia in $33 \%$ cases with range of $2.51 \pm$ $0.71 \mathrm{lac} /$ cumm. Singh et $\mathrm{al}^{8}$ show $86 \%$ cases with range of $2.5 \pm 1.51 \mathrm{lac} / \mathrm{cumm}$. In present study $80 \%$ cases with range of $2.31 \pm 0.30 \mathrm{lac} / \mathrm{cumm}$ is seen. This shows almost similar results in both study. Roa PC et $\mathrm{al}^{13}$ shows less result $33 \%$ patients.

In obstructive Jaundice: Rao PC et $\mathrm{al}^{13}$ show that out of 3 cases, 1 case (33.3\%) with low count and in present study, out of 20 cases 12 cases $(60 \%)$ show thrombocytopenia. Variation in result in different studies may be due to variation in number of cases studied and variation in different population of patients studied. Thrombocytopenia can occur due to sequestration of platelets in enlarged spleen, in cirrhosis with portal hypertension due to congestive splenomegaly. In cases of hepatitis, there is decreased platelet count due to premature removal of platelets from circulation, formation of antiplatelet antibodies, and disseminated intravascular coagulation. Reduced thrombopoietin level also contributes to thrombocytopenia in cirrhosis. ${ }^{16}$

In bleeder according to Spector and Corn et al,,${ }^{10}$ in study of 19 cases fibrinogen range was $253 \pm 35 \mathrm{mg} \%$ with control $325 \pm 160 \mathrm{mg} \%$. Stein SF et al ${ }^{14}$ show range of $271 \pm 104 \mathrm{mg} \%$ with control $285 \pm 22 \mathrm{mg} \%$ in 60 cases. Rastogi $\mathrm{P}$ et a ${ }^{11}$ show range of $196 \pm 25 \mathrm{mg} \%$ with control $281 \pm 28 \mathrm{mg} \%$ in 18 cases. In present study of 20 cases show range of $185 \pm 35 \mathrm{mg} \%$ with control of $220 \pm 20 \mathrm{mg} \%$ which is quiet comparable. In Non-bleeder, according to Spector and Corn et al ${ }^{10}$ count was $427 \pm 56 \mathrm{mg} \%$ in 22 cases. Rastogi $\mathrm{P}$ et al ${ }^{11}$ 
show $236 \pm 26 \mathrm{mg} \%$ in 12 cases. In present study of 20 cases show range of $215 \pm 35 \mathrm{mg} \%$ control range remain the same as in bleeders, this shows that the range was almost near the control range and minor cases show hypofibrinogenemia, which is quiet comparable. Increased fibrinolytic activity observed in cirrhotic may be due to increase in plasminogen activators or decrease in palsmin inhibitor. ${ }^{17}$ The former may be due to deficient hepatic clearance and the latter due to diminished production by the chronically diseased cirrhotic liver. In viral hepatitis, present study 40 case studied with range of $238.25 \pm 31.89 \mathrm{mg} \%$. This shows almost normal range. So hypofibrinogenemia is less observed in viral hepatitis. Ratnoff et $\mathrm{al}^{6}$ suggested that rapid clot lysis was seldom seen in patients of viral hepatitis.

\section{Conclusion}

We could conclude that various abnormalities of coagulation tests vary greatly with different liver disorders, duration of the disorders and their severity. In liver cirrhosis BT show normal range. But the mean value for bleeder is higher than non-bleeder. In viral Hepatitis and obstructive Jaundice, BT shows normal range. Prothrombin Time shows marked significant value in all liver diseases. In cirrhosis Bleeder shows elevation of prothrombin time in $90-100 \%$ cases \& nonbleeder shows $50-55 \%$ cases. In $87 \%$ cases of viral Hepatitis, $100 \%$ cases of obstructive Jaundice show rise in PT. APTT is quiet significant in liver Diseases. In Cirrhosis, bleeder show elevation of APTT in 65-90\%, non-bleeder show $30 \%$ cases, In viral Hepatitis decreased number of case $(40 \%)$ show rise in APTT and In obstructive Jaundice moderate number of cases (60\%) show rise in APTT. In Cirrhosis bleeders show severe degree of thrombocytopenia in $60-100 \%$ cases and non-bleeders show mild degree of thrombocytopenia in almost $100 \%$ cases. In viral Hepatitis \& obstructive Jaundice moderate number of cases $(75 \%)$ show mild thrombocytopenia. In Cirrhosis bleeders show moderate to severe degree of hypofibrinogenemia in $60 \%$ cases while non-bleeder show moderate degree hypofibrinogenemia in $15 \%$ cases. In viral Hepatitis and obstructive Jaundice mild degree of hypofibrinogenemia (10\%-15\%) seen. It suggests fibrinogen has not much significant value in viral Hepatitis \& obstructive jaundice.

Study of coagulation profile can help in assessing hepatic cell function and detecting cellular injury. Prolongation of PT and APTT in advancing liver cirrhosis indicates a damage of liver parenchyma resulting in decreased production of coagulation proteins with increased risk of bleeding tendencies, which can be detected before these ensue, by the determination of PT and APTT levels. Thus, preventing patients from landing in life-threatening bleeding complications is possible.

\section{References}

1. Reza SSM. Coagulation activity in liver disease. Internet Journal of Medical Update. 2009;4(2):19-23.

2. Rverter JC. Abnormal hemostasis tests and bleeding in chronic liver disease: are they related? Yes J Thromb heamost. 2006;4(4):717-20. doi: 10.1111/j.15387836.2006.01887.x

3. Tripodi A. Tests of coagulation in liver disease. Clin Liver Dis. 2009;13(1):55-61. doi: 10.1016/j.cld.2008.09.002.

4. Thachil J. Relevance of clotting tests in liver disease. Postgrad Med J. 2008;84(990):177-81. doi: 10.1136/pgmj.2007.066415.

5. Lemberg A, Benochia L, Pierangeli N. Comparative study of hemostatic changes in acute viral hepatitis and terminal cirrhosis. Acta Gastroenterol Latinoam. 1982;12(4):371-5.

6. Ratnoff (1949) studies on a protelytic enzymes in human plasma Bulletein of John Hopkin Hospital 84:29 Quoted ref. No. I

7. Donaldson GW, Davies SH, Darg A, Richmond J. Coagulation factors in chronic liver disease. J Clin Pathol. 1969;22(2):199-204.

8. Singh DS, Dube B., Gupta JP. Hepatic Cirrhosis in varanasi (A haemostatic approsial). J Indian Med Assoc. 1977;69(2):26-30.

9. Koller F. (1954) ubedic. Bodeuting des Antithrombin Helvetica MedicaActa 14:263 Quoted Ref. No. 1.

10. Spector I, Corn M. Laboratory Tests of Hemostasis The Relation to Hemorrhage in Liver Disease. Arch Intern Med. 1967;119(6):577-582. doi:10.1001/archinte.1967.00290240099006

11. Rastogi P, Gupta SC, Bhist D. Coagulation studies in Patients with Cirrhosis of liver: Bleeders Vs Non Bleeders. Indian J Pathol Microbiol 1990 Oct;33(4):3237. PMID:2132499.

12. Clark R, Rake MO, Flute PT, Williams R. Coagulation abnormality in acute liver failure; pathogenetic and therapeutic implications. Scand J Gastroentrol Suppl. 1973;19:63-70.

13. Roa PC, Manorama S. Platelet Function in Liver disorders. Indian J Med Res. 1974;62(4):227-30.

14. Stein SF, Harker LA. Kinetics and functional studies of platelets fibrinogen and plasma fibrinogen in patient hepatic cirrhosis. J Lab Clin Med. 1982;99(2):217-30.

15. Harker LA, Finch CA. Thrombokinetics in man. J Clin Inverst. 1969;48(6):963-74. Doi: 10.1172/JCI106077

16. Shah SN, Jansari T. Coagulation profile in liver disease a study of 100 cases. Gujarat Med J. 2014;69 (1):37-40.

17. Tytg G., Collen D, De Vreker R, Verstraete M. Investigation of fibrinolytic system in liver Cirrhosis. Acta Haematol. 1968;40(5):265-74. Doi:10.1159/000208914.

How to cite this article: Patel P, Mangar U, Patel R.D. Comparative study of coagulation profile in liver disease in tertiary care hospital. Indian J Pathol Oncol. 2018;5(4):554-557. 